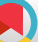

\title{
Protective Effect of Quercetin on Morphological and Histometrical Changes of Placenta in Streptozotocin-Induced Diabetic Rat
}

\author{
Mohammad Mehdi Shamsi ${ }^{1}$, Reza Ranjbar ${ }^{1,}{ }^{,}$, Mahmood Khaksary Mahabady ${ }^{1}$, Mohammad Reza \\ Tabandeh $^{2}$, Kaveh Khazaeel ${ }^{1}$ and Hossein Najafzadeh ${ }^{3}$ \\ ${ }^{1}$ Department of Anatomy and Embryology, Faculty of Veterinary Medicine, Shahid Chamran University of Ahvaz, Ahvaz, Iran \\ ${ }^{2}$ Department of Biochemistry and Molecular Biology, Faculty of Veterinary Medicine, Shahid Chamran University of Ahvaz, Ahvaz, Iran \\ ${ }^{3}$ Molecular Biology Research Center, Health Research Institute, Babol University Medical Sciences, Babol, Iran \\ "Corresponding author: Department of Anatomy and Embryology, Faculty of Veterinary Medicine, Shahid Chamran University of Ahvaz, Ahvaz, Iran. Email: \\ dabir120@yahoo.com
}

Received 2019 January 02; Revised 2019 June 07; Accepted 2019 August 05.

\begin{abstract}
Background: Maternal diabetes is a metabolic disorder among pregnant mothers that increases the risk of developing growth disorders in the fetus and the placenta. Placental deformity and dysfunction were reported in some studies. These changes have been related to oxidative stress. Quercetin is a component of the flavonoids group that can be found in vegetables, fruits, tea, and herbal supplements and has anti-inflammatory, anti-bacterial, anti-oxidant, and anti-diabetic properties.

Objectives: In this experimental study, prophylactic effect of quercetin was evaluated for structural changes of the placenta in diabetic rats.

Methods: Twenty-four pregnant Wistar rats were divided equally into four groups, including control, quercetin, diabetic, and quercetin-treated diabetic groups. Diabetes was induced by streptozotocin injection $(50 \mathrm{mg} / \mathrm{kg} / \mathrm{IV})$, then male rats for mating were put together with female rats. Quercetin was administered ( $75 \mathrm{mg} / \mathrm{kg} /$ gavage), on 0, 7, 14, and 20 days of gestation. On 20 th gestation day, the rats from all groups were anesthetized and laparotomized, then the placenta tissue was harvested. In the following, tissue section was stained by H\&E and were analyzed histologically.

Results: The weight, thickness and diameter of placenta in the diabetic group were increased but there was no significant difference compared to the quercetin treatment. The mean of the labyrinth zone, the number of trophoblastic giant cells and glycogen cells increased in the diabetic group and quercetin significantly reduced these parameters in diabetic rats $(\mathrm{P}<0.05)$. In addition, the mean of junctional zone decreased in the diabetic group, while quercetin increased it $(\mathrm{P}<0.05)$.

Conclusions: The results suggest that quercetin has a protective effect on cell proliferation and preservation of placental morphology in pregnant diabetic rats.
\end{abstract}

Keywords: Quercetin, Diabetes Mellitus, Placenta, Rat

\section{Background}

Gestational diabetes mellitus (GDM) is a syndrome characterized by defects associated with fetal growth, placental dissonance, and increased dignity of reproductive problems such as steroidogenesis, anovulation, and involuntary abortions (1). The presence of diabetes during pregnancy has been related to some problems for the placenta, including the enhancement of weight and size (2). Diabetes mellitus is one of the ordinary metabolic disturbance in pregnant women and enhance the risk of after labor deficiency and childhood sickness (3). The placenta plays a major role in the growth of the fetus, including metabolism and transmission of several types of food and excretory products, the transfer of electrolytes and the swapping of respiratory gases, the production of diverse hormones, antibodies and the attachment of the fetus to the wall of the uterus $(4,5)$. Placenta in mammals is divided into two types of choriovitelline and chorioallantoic according to the fetal membrane and is a complex organ in the embryonic course that plays a different function during the development of the fetus $(5,6)$. There are three main parts of the rat placenta, which are called the Basal part, the Labyrinth part, and the decidual part. Multiple types of cells are involved in the formation of the base part, including trophoblast stem cells, trophoblast giant cells, and glycogen cells $(7,8)$. In diabetic mothers, increasing the blood glucose levels throughout the lifetime of the embryo can cause placental obstacles and endanger their in- 
trauterine evolution (9). Diabetes mellitus increases the size of the placenta. Enlargement of the placenta in a diabetic mother, known as placentomegalia, has been related to a change placental histology and cellularity. Placentomegalia has been reported in humans and rats (10). Diabetes mellitus during pregnancy increases the junctional and labyrinth zone thickness and the number of giant trophoblast cells (11). The induction of diabetes in rodents with Streptozotocin (STZ) is the best and vast pattern of pilot diabetes with the method determined through endogenous chronic oxidative stress, which results from hyperglycemia. In diabetic rats, hyperglycemia due to experimental situation at the end of pregnancy results in weight loss (12). Streptozotocin-treated diabetic rats have a placenta size and embryo weight higher than normal rats. These mice often produce macrosomal embryos $(12,13)$. Antioxidant compounds such as vitamins $C$ and $E$ reduce indices of oxidative stress in women and barricade oxidative stress caused by hypoxia in mouse placenta $(14,15)$.

Flavonoids are a group of natural compounds vastly used as secondary metabolites by the plant kingdom. They have been known for having worthwhile clinical advantages, such as anti-inflammatory, anti-allergic, antiviral, antibacterial, and antitumor functions (16). Quercetin is a member of the flavonoids family with antioxidant properties, which is found in vegetables, fruits, tea, and food supplements. It barricades oxidant damage and cell death through several mechanisms, such as cleaning oxygen radicals $(17,18)$. Quercetin prevents oxidative damage and cell death by several specific mechanisms, including the removal of oxygen radicals $(18,19)$ and defense against lipid peroxidation (19). Quercetin is qualified for preventing biomolecular oxidation and it can change antioxidant defense pathways in vivo and in vitro (20).

\section{Objectives}

The aim of the present study was to investigate the possible protective effect of quercetin on histomorphometric changes on diabetic rats' placenta.

\section{Methods}

\subsection{Animals and Drug}

Forty adult female healthy Wistar rats, 3 to 4 months of age, weighting 200 to $220 \mathrm{~g}$ were purchased (JundiShapour Laboratory Animal Center, Ahvaz, Iran). They were kept under standard laboratory conditions with $12 \mathrm{~h}$ light/dark cycle at a temperature of $23 \pm 2^{\circ} \mathrm{C}$ with a relative humidity of $45.00 \%$ to $55.00 \%$ and free access to food pellets (Pars Animal Feed Co, Tehran, Iran) and tap water ad libitum.

\subsection{Induction of Diabetes}

The diabetic state was induced in female rats, by STZ (Sigma-Aldrich, St. Louis, USA.). Streptozotocin was dissolved in normal saline and administered by intravenous (i.v.) injection at a dose of $50 \mathrm{mg} / \mathrm{kg}(21,22)$. Subsequently, the blood glucose was measured after a week using a glucometer and via tail vein blood samples. The Wistar rats with blood glucose levels higher than $250 \mathrm{mg} / \mathrm{dl}$ were considered to be diabetic.

The study was approved by the Ethical Review Committee, Faculty of Veterinary Medicine, Shahid Chamran University of Ahvaz, Iran (approval ref No. EE/97.24.3/49902/scu.ac.ir). The experimental procedures were performed according to the guiding principles of the Institute for Laboratory Animal Research in Guide for the Care and Use of Laboratory Animals.

Three female and one male adult Wistar rats were kept for mating overnight in one cage. When a vaginal plug was found in the morning of the following day; this concerned the copulation day as zero day gestation (1).

Twenty-four pregnant Wistar rats were randomly assigned to four groups as follows:

1 - The control group received normal saline on days 0 , 7,14 , and 20 of the gestation.

2- Normal saline was orally administered to pregnant diabetic rats of the third group on days $0,7,14$, and 20 of the gestation (diabetic control group)

3- Quercetin (Sigma-Aldrich)-treated groups were given quercetin (75 mg/kg/gavage) on days $0,7,14$, and 20 of the gestation.

4- Quercetin + diabetic group: quercetin was administered by gavage ( $75 \mathrm{mg} / \mathrm{kg}$ ) to pregnant diabetic rats in the fourth group on days $0,7,14$, and 20 of the gestation.

The rats of all groups were anesthetized and laparotomized on 20th gestation day (a few hours after the last injection), then the uterus horn was torn and placentas were removed to be weighed.

\subsection{Histological Assessment}

The placenta's tissue weight, diameter, and thickness were measured on 20 days of gestation (a few hours after the last injection), then the placentas were fixed in phosphate-buffered $10 \%$ formalin and the samples were washed and dehydrated in ascending grades of alcohol, cleared in xylene and embedded in paraffin wax. Sections (5 $\mu$ thick) were stained by hematoxylin and eosin (H\&E) prepared from placenta by a microtome (Did sabz, 4055, Urmia, Iran). Microscopic Digital research (Nikon, Photolab 20 ENG. CO., Japan) was used to evaluate the tissue sections and capture tissue images. 


\subsection{Statistical Analysis}

Comparisons between groups were analyzed with oneway ANOVA using SPSS 16.0 statistical analysis software. Data were presented as Mean \pm SEM. In all tests, $\mathrm{P}<$ 0.05 was considered statistically significant between the groups for placental decidua, weight, thickness, diameter, length of the junctional zone (JZ) and labyrinth zone (LZ), number of trophoblast giant cells (TGC), and glycogen cells (GC). All statistical analyses were done by the software SPSS, version 16 (SPSS; Chicago, IL, USA). P $<0.05$ was considered statistically significant. The results have been represented as the mean \pm standard error of the mean (SEM).

\section{Results}

\subsection{Gross Observation}

There were no aborted fetuses in none of the groups but the percentage of resorbed fetuses were 4.16, 25.80, 4.25 , and $11.42 \%$ in the groups that received normal saline, diabetic, quercetin, and quercetin-treated diabetic group, respectively; therefore, quercetin decreased resorption rate. No maternal deaths were observed throughout the course of this study. Gross findings are summarized in Table 1 . The placentas weight, thickness, and diameter in the diabetic group was increased and the difference was significant in comparison to the control and the quercetin recipient groups $(\mathrm{P}<0.05)$, but the diabetic group showed no significant difference with the quercetin-treated group.

\begin{tabular}{|c|c|c|c|}
\hline Groups & Thickness, mm & Weight, $\mathbf{g}$ & Diameter, $\mathbf{m m}$ \\
\hline Control & $2.96 \pm 0.11^{\mathrm{C}}$ & $0.10 \pm 0.04^{\mathrm{B}}$ & $12.07 \pm 0.17^{\mathrm{B}}$ \\
\hline Quercetin & $2.84 \pm 0.11^{\mathrm{BC}}$ & $0.09 \pm 0.05^{B}$ & $12.49 \pm 0.16^{\mathrm{AB}}$ \\
\hline Diabetic & $4.33 \pm 0.51^{\mathrm{A}}$ & $0.15 \pm 0.04^{\mathrm{A}}$ & $13.71 \pm 0.53^{\mathrm{A}}$ \\
\hline $\begin{array}{l}\text { Diabetic + } \\
\text { Quercetin }\end{array}$ & $3.65 \pm 0.09^{\mathrm{AB}}$ & $0.13 \pm 0.09^{\mathrm{A}}$ & $12.77 \pm 0.17^{\mathrm{A}}$ \\
\hline $\begin{array}{l}{ }^{\mathrm{a}} \text { Values are } \\
{ }^{\mathrm{b}} \text { Means follc } \\
\text { the groups a } \\
0.05 \text { ). }\end{array}$ & $\begin{array}{l}\text { mean } \pm \text { SEM. } \\
\text { erent letters ind } \\
\text { mn using One-w }\end{array}$ & $\begin{array}{l}\text { te significant } \\
\text { ANOVA and HSI }\end{array}$ & $\begin{array}{l}\text { erences between } \\
\text { st-hoc tests }(P<\end{array}$ \\
\hline
\end{tabular}

\subsection{Light Microscopy}

From the viewpoint of histology, the rat placenta composed of the labyrinth zone, the junctional zone, and the decidua. In the junctional zone, three types of cells are comprised of spongiotrophoblast (STC), trophoblast giant cells (TGC), and glycogen cells (GC). The spongiotrophoblasts are immediately located above the trophoblastic giant cell layer located at the maternal-fetal placental interface. The glycogen cells form multiple small cell masses and develop into glycogen cell islands and are located among the spongiotrophoblast cells. The decidua is comprised of the mesometrial decidual cells ultimately (Figures 1 and 2).

The histological analysis revealed that the mean of decidua and labyrinth zone length in the diabetic group was significantly increased in severe maternal diabetes $(\mathrm{P}<$ 0.05) compared with the other groups, while the mean of junctional zone length in the diabetic group was significantly reduced $(\mathrm{P}<0.05)$. The mean number of TGCs and GCs in the diabetic group was significantly higher than the other groups $(\mathrm{P}<0.05)$, while the mean number of TGCs and GCs in the quercetin-treated diabetic group decreased significantly (Table 2 and Figure 2).

\section{Discussion}

The purpose of this study was to identify some morphological and histometrical changes in the placenta of streptozotocin-induced diabetic rats treated with quercetin. In the present study, morphological analysis of the diabetic rats showed a significant increase in placental weight, thickness, and diameter. The gross analysis showed weight, thickness, and diameter in the diabetic group was increased and significantly differed from the control and quercetin groups but there was no significant difference with the quercetin-treated diabetic group. There are reports that there is an increase in the amount of GC and large trophoblast cells in a placenta of diabetic rats $(10,23)$. The rodents mostly used as experimental models (Wistar rats) because animal models in diabetes and pregnancy are beneficial for research (24). Numerous studies have used different doses of alloxan and streptozotocin in rats to induce diabetes during pregnancy $(25,26)$.

Many studies show morphological changes in the spongiotrophoblast and GC size and structure in human and rat models of diabetes $(10,26)$. As well as a study of human placentas from diabetic pregnancies indicated that placental weight and cell proliferation were increased (27). In the current study, the histological analysis showed an increased amount of GC and TGC in the diabetic rats' placenta that similar findings were reported in previous studies $(28,29)$.

Diabetes elevates the retain of cell proliferation rate in labyrinth area, the number of STC and TGC in the late terms of pregnancy, which may illustrate the placentomegalia apperceive in some diabetic animals at the end of pregnancy. Further, diabetes is defined as an increased amount of GC and TGC (26). In the present study, we observe an alteration in Labyrinth zone (LZ) that shows this area is highly influenced by the hyperglycemic status and drawn. This result is consistent with previous reports $(1,30)$. In 

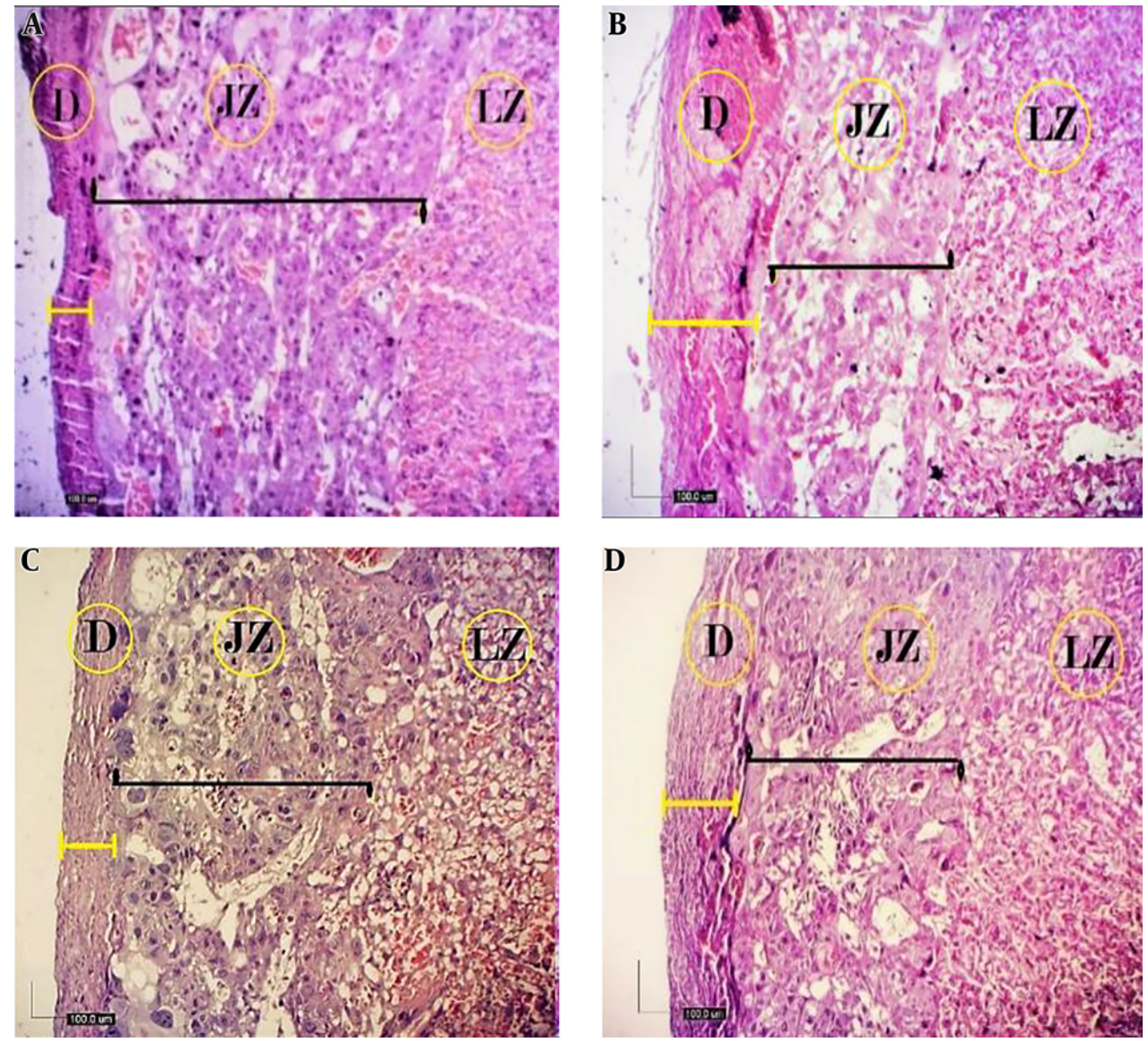

Figure 1. Histological structure of fetal placenta (20th day) in the studied groups (H\&E, 4X). A, control; B, diabetic; C, quercetin-treated diabetic; and D, quercetin. Three compartments of mature placenta: decidua (D), junctional zone (JZ), and labyrinth zone (LZ). The JZ in the placenta of diabetic rats was reduced in terms of thickness (black straight line), while decidua was increased (yellow straight line), but in the quercetin-treated diabetic, the thickness of the decidua has decreased and there was no significant difference compared with the control group (D).

\begin{tabular}{|c|c|c|c|c|c|}
\hline Groups & Decidua, um & $\mathrm{JZ}, \mathrm{um}$ & LZ, um & TGC, numb & GC, numb \\
\hline Control & $72.37 \pm 1.51^{\mathrm{B}}$ & $564.45 \pm 10.09^{B}$ & $2547.20 \pm 39.77^{C}$ & $1.20 \pm 0.08^{C}$ & $12.00 \pm 0.20^{C}$ \\
\hline Quercetin & $78.07 \pm 1.80^{\mathrm{B}}$ & $563.87 \pm 7.02^{B}$ & $2546.56 \pm 26.44^{C}$ & $1.12 \pm 0.06^{\mathrm{C}}$ & $11.40 \pm 0.22^{\mathrm{C}}$ \\
\hline Diabetic & $151.88 \pm 1.64^{\mathrm{A}}$ & $421.46 \pm 7.60^{\mathrm{C}}$ & $2959.99 \pm 35.08^{A}$ & $2.08 \pm 0.12^{\mathrm{A}}$ & $30.76 \pm 0.39^{A}$ \\
\hline Diabetic + Quercetin & $76.01 \pm 1.70^{\mathrm{B}}$ & $598.60 \pm 6.25^{\mathrm{A}}$ & $2786.85 \pm 22.04^{\text {B }}$ & $1.60 \pm 0.10^{\mathrm{B}}$ & $20.20 \pm 0.29^{B}$ \\
\hline
\end{tabular}

${ }^{\mathrm{a}}$ Values are expressed as mean $\pm \mathrm{SEM}$.

${ }^{\mathrm{b}}$ Means followed by different letters indicate significant differences between the groups at each column using One-way ANOVA and HSD post-hoc tests $(\mathrm{P}<0.05)$.

diabetic rats, the size of the placenta has been before displayed by the description of dry and wet placental weight (10). Also, other studies with the model of diabetic rats have shown alteration in the size of Labyrinth zone and the number of the STC and GC $(10,31)$.

Studies on the effects of maternal diabetes on placental expansion have shown an increase in the labyrinth layer in the placenta of diabetic rats $(6,32)$. Despite the fact that number of the GC, TGC, and length of LZ have increased but we demonstrated significant reduction of the JZ; however, it has been reported a reduction in the length of junctional zone for diabetic rats' placenta which can (It may be associated with an increase in the thickness of the decidua and its matrix) be linked to the STC differentiation (33). 

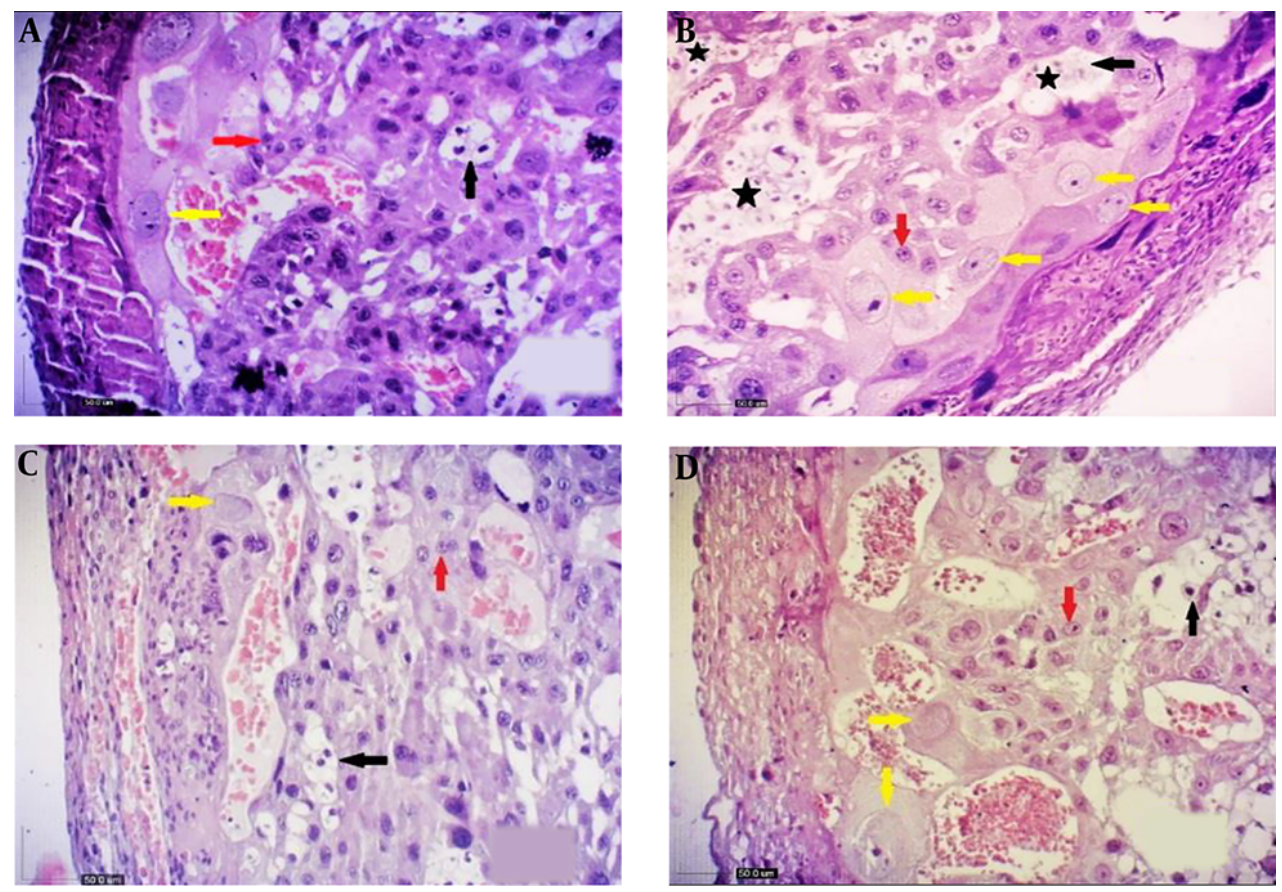

Figure 2. Comparison of changes in the cells of fetal placenta (20th day) in the studied groups (H\&E,10X). A, control; B, diabetic; C, quercetin-treated diabetic; and D, quercetin. Giant cells (yellow arrow), glycogen cells (black arrow), Sponglotrophoblast cells (red arrow) and as lakes of cells (black star). Increasing the number of giant cells (TGC) and glycogen cells (GC) is shown in diabetic group, which causes the accumulation of GCs (B), while a decrease was shown in the number of TGCs and GCs in the quercetin-treated diabetic group (D).

The findings of the current study demonstrated supportive effects of quercetin during gestational diabetes on some of placenta structures. There are a lot of reports about the importance and value of flavonoids, especially quercetin. The daily western diet possesses average flavonoids, of which quercetin comprises the main component (34). Studies of the chemical structures of flavonoids indicate that antioxidant activity may be related to the degree of hydroxylation as hydrogen giving free radical scavengers $(35,36)$. The use of quercetin can protect placental morphology and decrease oxidative stress, and serum glucose levels (30). This agent removes oxygen radicals $(17,18)$ and prevents oxidant damage and cell death $(36)$. Also, quercetin regulates the thickness of the labyrinth layer and the placenta vasculature in the mouse placenta (37). In addition, the quercetin improves the diabetesinduced changes in activities of superoxide dismutase and catalase (38). Other studies, which evaluated the effects of quercetin against oxidative stress, demonstrated that alanine aminotransferase and aspartate aminotransferase levels and glutathione (GSH), superoxide dismutase, catalase, and glutathione peroxidase activities were significantly decreased, and malondialdehyde levels increased as a result of oxidative stress, and it was reported that quercetin administration normalized all values and preserved the integrity of pancreatic $\beta$-cells $(39,40)$.

Another study indicated that quercetin might have an antioxidant effect and prevented the renal tubular damage and decreased oxidative stress arising from induced by chronic cadmium administration (41). The treatment with quercetin in diabetic rats causes an increased number of corpora lutea and maternal weight gain (23). Quercetin is a potential drug with antidiabetic and anti-hyperglycemic functions mediated by changes in the levels of glucose, cholesterol, and triglycerides (41). The findings propose that quercetin therapy has protective efficacy in diabetes by regressive oxidative stress and the maintenance of pancreatic-cell integrity (42).

The use of melatonin in pregnancy with undernutrition may reclaim placental usefulness by upregulating placental antioxidant enzymes, as well as reduced lipid peroxidation and uteroplacental antioxidant enzyme activities $(43,44)$.

Although we observed the protective effect of quercetin on thickness, diameter, and weight placenta in the diabetic group treated with quercetin, this effect was not significant compared to the diabetic group. In the present study, treatment with quercetin significantly 
reduced the LZ in diabetic rats, as well as the JZ that decreased in the diabetic rats was significantly increased. In terms of the decidua layer, we observed that the decidua layer showed an increase in thickness, which could not be correlated with the decrease in the thickness of the JZ, so a remarkable result of the present study was an increase in the thickness of the decidua layer.

\subsection{Conclusions}

In this study, we showed that STZ-induced diabetes during gestation caused abnormal placental development by disturbing the proliferation capacity of GC, TGC, as well as increased length of LZ and decidua layers but decreased the length of JZ. Quercetin therapy leads to the improvement of placental morphology and balancing the number of cells and their surroundings.

\section{Footnotes}

Authors' Contribution: All authors had an equal role in the design, work, statistical analysis, and manuscript writing.

Conflict of Interests: The authors declare no conflict of interest.

Ethical Approval: The study was approved by the Ethical Review Committee, Faculty of Veterinary Medicine, Shahid Chamran University of Ahvaz, Iran (approval ref No. EE/97.24.3/49902/scu.ac.ir).

Funding/Support: The authors are thankful to the research deputy of Shahid Chamran University of Ahvaz for financial funding of this study (Grant number of SCU.vB98.59).

\section{References}

1. Gul M, Bayat N, Cetin A, Kepekci RA, Simsek Y, Kayhan B, et al. Histopathological, ultrastructural and apoptotic changes in diabetic rat placenta. Balkan Med J. 2015;32(3):296-302. doi: 10.5152/balkanmedj.2015.15290. [PubMed: 26185719]. [PubMed Central: PMC4497697].

2. Desoye G, Gauster M, Wadsack C. Placental transport in pregnancy pathologies. Am J Clin Nutr. 2011;94(6 Suppl):1896S-902S. doi: 10.3945/ajcn.110.000851. [PubMed: 21543540].

3. Finer S, Mathews C, Lowe R, Smart M, Hillman S, Foo L, et al. Maternal gestational diabetes is associated with genome-wide DNA methylation variation in placenta and cord blood of exposed offspring. Hum Mol Genet. 2015;24(11):3021-9. doi: 10.1093/hmg/ddv013. [PubMed: 25634562].

4. Emmanouil-Nikoloussi EN, Nikoloussis E, Likartsis C, Goula O. Placenta blood barrier and retinoids: Histological and immunohistochemical (HSPs) study in Balb/C mice placentae. Reprod Toxicol. 2008;26(1):61. doi: 10.1016/j.reprotox.2008.05.015.

5. Longo LD, Reynolds LP. Some historical aspects of understanding placental development, structure and function. Int J Dev Biol. 2010;54(23):237-55. doi: 10.1387/ijdb.082774ll. [PubMed: 19876830].
6. Zorn TM, Zuniga M, Madrid E, Tostes R, Fortes Z, Giachini F, et al. Maternal diabetes affects cell proliferation in developing rat placenta. Histol Histopathol.2011;26(8):1049-56. doi:10.14670/HH-26.1049. [PubMed: 21692037]

7. Huppertz B, Burton G, Cross JC, Kingdom JC. Placental morphology: From molecule to mother - a dedication to Peter Kaufmann - a review. Placenta. 2006;27 Suppl A:S3-8. doi: 10.1016/j.placenta.2006.01.007. [PubMed: 16542720].

8. Cross JC, Baczyk D, Dobric N, Hemberger M, Hughes M, Simmons DG, et al. Genes, development and evolution of the placenta. Placenta. 2003;24(2-3):123-30. doi: 10.1053/plac.2002.0887.

9. Boitard $\mathrm{C}$. The differentiation of the immune system towards antiislet autoimmunity. Clinical prospects. Diabetologia. 1992;35(12):110112. doi: 10.1007/bfo0401362. [PubMed: 1478361].

10. Giachini FR, Carriel V, Capelo LP, Tostes RC, Carvalho MH, Fortes $\mathrm{ZB}$, et al. Maternal diabetes affects specific extracellular matrix components during placentation. I Anat. 2008;212(1):31-41. doi: 10.1111/j.1469-7580.2007.00839.x. [PubMed: 18067546]. [PubMed Central: PMC2423385].

11. Evers IM, Nikkels PG, Sikkema JM, Visser GH. Placental pathology in women with type 1 diabetes and in a control group with normal and large-for-gestational-age infants. Placenta. 2003;24(8-9):819-25. doi: 10.1016/s0143-4004(03)00128-0. [PubMed:13129678].

12. Serman L, Zunic I, Vrsaljko N, Grbesa D, Gjurcevic E, Matasin Z, et al. Structural changes in the rat placenta during the last third of gestation discovered by stereology. Bosn J Basic Med Sci. 2015;15(1):21-5. doi: 10.17305/bjbms.2015.1.244. [PubMed: 25725140]. [PubMed Central: PMC4365672].

13. Aljunaidy MM, Morton JS, Kirschenman R, Phillips T, Case CP, Cooke $\mathrm{CM}$, et al. Maternal treatment with a placental-targeted antioxidant (MitoQ) impacts offspring cardiovascular function in a rat model of prenatal hypoxia. Pharmacol Res. 2018;134:332-42. doi: 10.1016/j.phrs.2018.05.006. [PubMed: 29778808].

14. Chappell LC, Seed PT, Kelly FJ, Briley A, Hunt BJ, Charnock-Jones DS, et al. Vitamin C and E supplementation in women at risk of preeclampsia is associated with changes in indices of oxidative stress and placental function. Am J Obstet Gynecol. 2002;187(3):777-84. doi 10.1067/mob.2002.125735. [PubMed:12237663].

15. Richter HG, Camm EJ, Modi BN, Naeem F, Cross CM, Cindrova-Davies $\mathrm{T}$, et al. Ascorbate prevents placental oxidative stress and enhances birth weight in hypoxic pregnancy in rats. J Physiol. 2012;590(6):137787. doi: 10.1113/jphysiol.2011.226340. [PubMed: 22289909]. [PubMed Central: PMC3382329].

16. Szkudelski T. The mechanism of alloxan and streptozotocin action in B cells of the rat pancreas. Physiol Res. 2001;50(6):537-46. [PubMed: 11829314].

17. Bors W, Heller W, Michel C, Saran M. Flavonoids as antioxidants: Determination of radical-scavenging efficiencies. Methods Enzymol. 1990;186:343-55. doi:10.1016/0076-6879(90)86128-i. [PubMed: 2172711].

18. Inal ME, Akgun A, Kahraman A. Radioprotective effects of exogenous glutathione against whole-body gamma-ray irradiation: age- and gender-related changes in malondialdehyde levels, superoxide dismutase and catalase activities in rat liver. Methods Find Exp Clin Pharmacol.2002;24(4):209-12. doi:10.1358/mf.2002.24.4.678452. [PubMed: 12092007].

19. Laughton MJ, Evans PJ, Moroney MA, Hoult JR, Halliwell B. Inhibition of mammalian 5-lipoxygenase and cyclo-oxygenase by flavonoids and phenolic dietary additives. Relationship to antioxidant activity and to iron ion-reducing ability. Biochem Pharmacol. 1991;42(9):167381. doi: 10.1016/0006-2952(91)90501-u. [PubMed: 1656994].

20. Morand C, Crespy V, Manach C, Besson C, Demigne C, Remesy C. Plasma metabolites of quercetin and their antioxidant properties. Am J Physiol. 1998;275(1):R212-9. doi: 10.1152/ajpregu.1998.275.1.R212. [PubMed: 9688981]. 
21. Uriu-Hare JY, Stern JS, Keen CL. Influence of maternal dietary Zn intake on expression of diabetes-induced teratogenicity in rats. Diabetes. 1989;38(10):1282-90. doi: 10.2337/diab.38.10.1282. [PubMed: 2792578].

22. Volpato GT, Calderon IM, Sinzato S, Campos KE, Rudge MV, Damasceno DC. Effect of Morus nigra aqueous extract treatment on the maternal-fetal outcome, oxidative stress status and lipid profile of streptozotocin-induced diabetic rats. J Ethnopharmacol. 2011;138(3):691-6. doi:10.1016/j.jep.2011.09.044. [PubMed: 21986227].

23. Farias PS, dos Santos Souza K, Marçal AC, Fioretto ET, Aires MB. Altered placental morphology and VEGF expression in diabetic rats. Microscopy Adv Sci Res Educ. 2014:285-90.

24. Vambergue A, Fajardy I. Consequences of gestational and pregestational diabetes on placental function and birth weight. World J Diabetes. 2011;2(11):196-203. doi: 10.4239/wjd.v2.i11.196. [PubMed: 22087356]. [PubMed Central: PMC3215769].

25. Oh W, Gelardi NL, Cha CJ. The cross-generation effect of neonatal macrosomia in rat pups of streptozotocin-induced diabetes. Pediatr Res. 1991;29(6):606-10. doi: 10.1203/00006450-199106010-00016. [PubMed: 1866217].

26. Palomar-Morales M, Baiza LA, Verdin-Teran L, Roman-Ramos R, Altamirano-Lozano M, Mendez JD. Fetal development in alloxantreated rats. Reprod Toxicol. 1998;12(6):659-65. doi: 10.1016/s08906238(98)00043-4. [PubMed: 9875699].

27. Verma R, Mishra S, Kaul JM. Cellular changes in the placenta in pregnancies complicated with diabetes. Int J Morphol. 2010;28(1):259-64.

28. Padmanabhan $\mathrm{R}$, Shafiullah $\mathrm{M}$. Intrauterine growth retardation in experimental diabetes: possible role of the placenta. Arch Physiol Biochem. 2001;109(3):260-71. doi: 10.1076/apab.109.3.260.11596. [PubMed: 11880931].

29. Gewolb IH, Merdian W, Warshaw JB, Enders AC. Fine structural abnormalities of the placenta in diabetic rats. Diabetes. 1986;35(11):1254-61 doi: 10.2337/diab.35.11.1254. [PubMed: 3758495].

30. Erşahin A, Hocaoglu M, Demirer S, Cengiz F. Quercetin improves metabolic sequels and placental morphology in streptozotocin-induced diabetic rats. Perinatal J. 2016;24(3):14755. doi: 10.2399/prn.16.0243007.

31. Prager R, Abramovici A, Liban E, Laron Z. Histopathological changes in the placenta of streptozotocin induced diabetic rats. Diabetologia. 1974;10(1):89-91. doi: 10.1007/bfo0421419. [PubMed: 4275638].

32. Acar N, Korgun ET, Cayli S, Sahin Z, Demir R, Ustunel I. Is there a relationship between PCNA expression and diabetic placental development during pregnancy? Acta Histochem. 2008;110(5):408-17. doi 10.1016/j.acthis.2007.11.011. [PubMed: 18377963].

33. Salbaum JM, Kruger C, Zhang X, Delahaye NA, Pavlinkova G, Burk DH et al. Altered gene expression and spongiotrophoblast differentiation in placenta from a mouse model of diabetes in pregnancy. Dia- betologia. 2011;54(7):1909-20. doi: 10.1007/s00125-011-2132-6. [PubMed: 21491160]. [PubMed Central: PMC3882064].

34. Duthie SJ, Dobson VL. Dietary flavonoids protect human colonocyte DNA from oxidative attack in vitro. Eur J Nutr. 1999;38(1):28-34. doi: 10.1007/s003940050043. [PubMed: 10338685].

35. Rice-Evans CA, Miller NJ, Paganga G. Structure-antioxidant activity relationships of flavonoids and phenolic acids. Free Radic Biol Med. 1996;20(7):933-56. doi: 10.1016/0891-5849(95)02227-9. [PubMed: 8743980].

36. Plumb GW, Price KR, Williamson G. Antioxidant properties of flavonol glycosides from green beans. Redox Rep. 1999;4(3):123-7. doi: 10.1179/135100099101534800. [PubMed:10496415].

37. Prater MR, Laudermilch CL, Liang C, Holladay SD. Placental oxidative stress alters expression of murine osteogenic genes and impairs fetal skeletal formation. Placenta. 2008;29(9):802-8. doi: 10.1016/j.placenta.2008.06.010. [PubMed: 18675455]. [PubMed Central: PMC2583463].

38. Mahesh T, Menon VP. Quercetin allievates oxidative stress in streptozotocin-induced diabetic rats. Phytother Res. 2004;18(2):123-7. doi: 10.1002/ptr.1374. [PubMed: 15022163].

39. Adewole SO, Caxton-Martins EA, Ojewole JA. Protective effect of quercetin on the morphology of pancreatic beta-cells of streptozotocin-treated diabetic rats. Afr J Tradit Complement Altern Med. 2006;4(1):64-74. doi: 10.4314/ajtcam.v4i1.31196. [PubMed: 20162074]. [PubMed Central: PMC2816429].

40. Morales AI, Vicente-Sanchez C, Sandoval JM, Egido J, Mayoral P, Arevalo MA, et al. Protective effect of quercetin on experimental chronic cadmium nephrotoxicity in rats is based on its antioxidant properties. Food Chem Toxicol. 2006;44(12):2092-100. doi: 10.1016/j.fct.2006.07.012. [PubMed: 16962696]

41. Braga CP, Baptista RFF, Peixoto FB. Effects of quercetin administration on the pregnancy outcome of diabetic rats.J Diabete Metab. 2012;3(2). doi: 10.4172/2155-6156.1000180.

42. Coskun O, Kanter M, Korkmaz A, Oter S. Quercetin, a flavonoid antioxidant, prevents and protects streptozotocin-induced oxidative stress and beta-cell damage in rat pancreas. Pharmacol Res. 2005;51(2):117-23. doi: 10.1016/j.phrs.2004.06.002. [PubMed: 15629256].

43. Richter HG, Hansell JA, Raut S, Giussani DA. Melatonin improves placental efficiency and birth weight and increases the placental expression of antioxidant enzymes in undernourished pregnancy. $J$ Pineal Res. 2009;46(4):357-64. doi: 10.1111/j.1600-079X.2009.00671.x. [PubMed: 19552758].

44. Olayaki L. The role of melatonin on uteroplacental antioxidant enzymes activities and fetal growth retardation in diabetic rats (910.1). FASEB J. 2014;28(1_supplement):910.1. 